\title{
CHROMOBLASTOMYCOSIS SIMULATING RHINOSPORIDIOSIS IN A PATIENT FROM CEYLON
}

BY

\author{
W. St. C. SYMMERS \\ From Charing Cross Hospital and Medical School, London
}

(RECEIVEd FOR PUBLICATION JULY 20, 1959)

\begin{abstract}
A case of chromoblastomycosis confined to the mucous membrane of one side of the nasal septum is reported. The organism was not cultivated, but its characteristics in histological preparations were typical of those of the organisms in sections of cutaneous lesions known to be caused by Phialophora pedrosoi and related fungi. The diagnosis is considered to have been justified in spite of the great rarity of mucosal involvement in chromoblastomycosis and of the complete absence of lesions in the skin.

The patient was a Sinhalese student working in London. He had first noticed the lesion before he left Ceylon, but the symptoms of nasal obstruction and bleeding were not sufficient to make him seek medical advice until two years later. If it is correct to assume that he contracted the infection in Ceylon his case is only the second on record in which there has been reason to suggest that Ceylon has been the geographical source of chromoblastomycosis.

The lesion was excised and its site cauterized. There has been no sign of recurrence of the infection during the two years that have passed since the operation.
\end{abstract}

The chromoblastomycoses are infections caused by naturally pigmented (" dematiaceous") fungi : because of their pigmentation these organisms appear as yellowish-brown elements which are readily seen microscopically, even in unstained preparations of infected material, including histological sections. There are two clinicopathological types of chromoblastomycosis, cutaneous and cerebral ; several species of the pigmented fungi have been isolated from cases of these infections.

The main pathogenic species are Phialophora pedrosoi, Phialophora verrucosa, Phialophora compacta, and Cladosporium trichoides; of these, Phialophora pedrosoi (which is also known by the synonyms Hormodendrum pedrosoi and Fonsecaea pedrosoi) is by far the commonest. Cladosporium trichoides has so far only been identified in lesions of the central nervous system. In cutaneous chromoblastomycosis the organisms occur in the tissues in the form of rounded, sporelike structures (chlamydospores), which have a distinct cell wall and are often septate. Germinating chlamydospores with a short sprout of promycelium are seen very occasionally, but true mycelium formation does not occur in the lesions in the skin. In contrast, mycelium is characteristically abundant in the lesions of cerebral chromoblastomycosis.

\section{Cerebral Chromoblastomycosis}

Cerebral chromoblastomycosis (cerebral cladosporiosis) is an exceptionally rare infection which has been recognized only comparatively recently. It has been mortal in 14 of the 15 recorded cases. It is not usually associated with skin involvement, and in further contrast with cutaneous chromoblastomycosis its occurrence is not restricted to hot climates. The cases which have been recognized in temperate lands include one case in Britain (Symmers, 1960).

\section{Cutaneous Chromoblastomycosis}

Cutaneous chromoblastomycosis is ordinarily met with only in tropical or subtropical lands, although a small number of autochthonous cases has been recorded in the colder lands of northeastern Europe. In most cases it is confined to one limb, usually a leg, and it is characterized by the slow development of nodular or warty, granulomatous masses which, during a period of many years, extend to cover a considerable part of the affected limb. The lesions tend to bleed easily and are prone to secondary bacterial infection. Involvement of the lymphatics in the granulomatous process eventually obstructs the lymph flow, and this may cause a lymphoedematous 
elephantiasis. The infection very rarely extends from the skin into underlying structures or to the lymph nodes, and if lymphadenitis develops it is virtually always the result of secondary bacterial infection.

Chromoblastomycotic lesions in other parts of the body, the result of spread through the blood stream, have been recognized only in most exceptional cases of the cutaneous disease. In the case of Carrión and Koppisch (1933) the skin infection was on one leg and there were metastatic lesions in the subcutaneous tissue of the opposite leg and of one arm. In the case of Fukushiro, Kagawa, Nishiyama, and Takahashi (1957) multiple brain abscesses developed as a complication of infection of the skin of the face; Phialophora pedrosoi was isolated from the cerebral and cutaneous lesions. This is the only case of cerebral infection

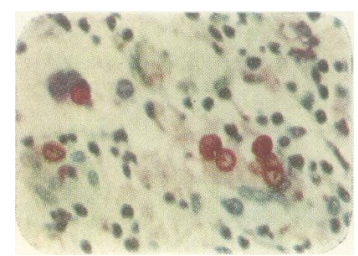

FIG. 1

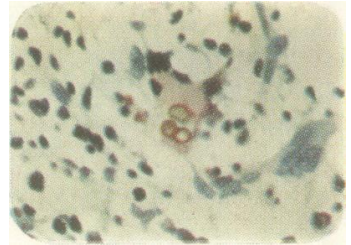

FIG. 2
FIG. 1.-A cluster of chlamydospores in a multinucleated giant cell in the right-hand half of the field; septation is clearly seen in the organism nearest to the centre of the picture. Single chlamydospores are present in two other giant cells. Note how the natural golden-brown pigment of the organisms distinctly underlies and alters the colour associated with the positive Schiff reaction. Periodic-acid-Schiff reaction; Mayer's haemalum $\times 220$. (Kodachrome)

FIG. 2.-Multinucleated giant cell containing a cluster of brown chlamydospores. Mayer's haemalum and eosin. $\times 220$. (Kodachrome)

occurring as a complication of cutaneous chromoblastomycosis that has been reported; permission was not available to examine any part of the body post mortem except the brain, and it was therefore impossible to tell whether lesions were present elsewhere. Visceral lesions have not been recorded in any other case of cutaneous chromoblastomycosis. It should be stressed that cutaneous chromoblastomycosis in fact is not ordinarily a direct hazard to the patient's life, although considerable disability may eventually result.

Cutaneous chromoblastomycosis was first recognized in Brazil by Pedroso in 1911, but he did not publish his observations until nine years later (Pedroso and Gomes, 1920). The disease has proved to be most prevalent in the territories around the Caribbean Sea, and particularly in Puerto Rico, where it has been extensively studied by Carrión (1950), to whose work much of what is known about its manifestations and mycology is due. Cases have been recognized in most countries in the Americas, and are not very uncommon in parts of South Africa and in Madagascar and Queensland. Occasional cases have been reported from parts of China, India, Japan, the East Indies, and parts of North, East, and West Africa.

Only a very small number of cases has been reported in which the infection was contracted in Europe. The first of these was diagnosed in 1928 in Leningrad by Tschernjawski (1929): the patient, a Polish woman, had probably acquired the infection many years before when she fell from her horse into some scrub near Wilno (now Vilnius, Lithuania). Meriin (1930) gave the name Hormodendrum rossicum to the organism which he isolated from the lesion in Tschernjawski's case: this species, however, may well have been identical with Phialophora pedrosoi (Sonck, 1959b). By 1938, 14 cases had been recorded in Russia (Prokoptchouk, 1938), although it seems to be likely that the infection was not acquired in European parts of the Soviet Union in all these cases. Since then occasional further cases have been reported from the Soviet Union. The only autochthonous European cases to be recognized outside Russia were all diagnosed in Finland by Sonck (four cases-1954, 1959a, 1959b) and Järvi (one case, cited by Sonck, 1959a). Phialophora pedrosoi was isolated in four of these five Finnish cases; no growth was obtained in the fifth case.

The first case of cutaneous chromoblastomycosis to be diagnosed in Britain was recorded by Crow and Riddell (1954): the patient had come from Jamaica. I know of only one other case which has been recognized in Britain; this patient also came from Jamaica. His biopsy specimen was the source of the photomicrographs illustrated in Figs. 36 and 55 in an earlier publication (Symmers, 1958). Phialophora pedrosoi was isolated from both these cases.

Cutaneous chromoblastomycosis appears to originate with the direct inoculation of infective material into the skin as a result of minor penetrating injuries, abrasions, or the like. It is significant that the incidence of the disease is mainly in workers on the land who customarily go barefoot, and that the first lesions are usually on the foot. Phialophora verrucosa, one of the rarer fungi of cutaneous chromoblastomycosis, has been found in wood pulp (Martin, 1938), and there can be little doubt that the other organisms will also prove to occur as free-living saprophytes. 
Involvement of the mucous membranes, as in the case reported below, is an exceptionally rare manifestation of chromoblastomycosis. Isolated instances of lesions of the conjunctiva, nose, and larynx have been described (Lacaz, 1956). There was no disease of the skin in the case to be described. The diagnosis was made in London, and the case is therefore one of the very small number of cases of this infection which have been seen in Britain. The patient was a student from Ceylon; his symptoms began before he left his home in Colombo, and there seems therefore to be no doubt that the disease originated in that country. Only one other case has been reported in which chromoblastomycosis was believed to have been contracted in Ceylon. The patient was a Canadian airman who had served there for two years during the second world war: his lesion appeared before he left the island, and the diagnosis was made in Canada about four years later (Burns, 1950). The possibility that the Canadian patient acquired the infection in North America, or during calls ashore in South Africa and India on the way to Ceylon, cannot be excluded.

I am indebted to Professor G. R. Cooray, of the University of Ceylon, for the information that chromoblastomycosis has not to his knowledge been recognized in his country on other occasions. It is relevant that only three cases of presumed chromoblastomycosis have been recorded in India (Andleigh, 1953 ; Thomas, Job, and Hadley, 1957 ; Kakoti and Dey, 1957): I am indebted to Lieutenant-Colonel M. L. Ahuja, Medical Adviser to the High Commissioner for India in London, to Lieutenant-Colonel B. K. Sheorey, also of India House, London, and to Professor R. N. Chaudhuri, Director of the School of Tropical Medicine in Calcutta, for this information, and to the Administrator of King Edward Medical College in Lahore for the information that no case of chromoblastomycosis is known to have occurred in Pakistan.

\section{Case Report}

A young Sinhalese man, studying in London, came to hospital because of troublesome bleeding from a small mass which was partly obstructing the airway in one nostril. He had noticed the lesion first some two years earlier, a few weeks before he left his home in Colombo to come to England. He had never been out of Ceylon before then. At first there were no symptoms, and he noticed the little mass-which could be seen through the nostril-quite by accident. It grew very slowly, and it was not until after about nine months that he began to have a sensation of pressure and obstruction in the nose. Some dry crusting formed around the lesion, and in gently attempting to clear the crusts away with a probe he caused free bleeding on a number of occasions. He became accustomed to the slight discomfort, and apart from a tendency to bleeding if he blew his nose too forcefully he had no reason to feel particularly concerned about it. On some occasions, however, the bleeding was difficult to stop, and his nose filled with blood clot which he was afraid might become infected: he therefore felt it advisable to have something done about the condition.

Examination showed a fairly soft, dusky red, sessile mass projecting from the nasal septum and filling the airway between it and the anterior part of the lowest turbinate. The surface of the lesion was smooth and sparsely patterned with minute, rounded flecks reminiscent of the similar appearance of the lesions of rhinosporidiosis. As the patient had come from Ceylon, where rhinosporidiosis is known to occur, this diagnosis was made clinically with considerable confidence. The lesion was dissected out with little difficulty, and the site was cauterized with the intention of destroying any remaining organisms. No other lesions were found. No attempt was made to put up cultures; the whole of the excised tissue was fixed in formol-saline.

The specimen consisted of about a dozen pieces of soft, vascular tissue which occupied in all a volume of just over $3 \mathrm{c.cm}$. Sections showed no sign whatever of rhinosporidiosis, and to confirm this the whole of the tissue was examined histologically in step sections. Instead of the expected sporangia and spores of Rhinosporidium almost every high-power field contained dark golden-brown, rounded bodies, each about $10 \mu$ in diameter, which were present singly or in clusters of up to six or eight (see figures). Many of these bodies were divided by one or two septa ; no hyphae were found. The appearances were typical of the chlamydospores (so-called "sclerotic bodies ") of the fungi which cause cutaneous chromoblastomycosis, as was readily confirmed on comparing them with the organisms in histological preparations from several known cases of Phialophora pedrosoi infection. It may be noted that the morphological appearances of the chlamydospores in infected tissues do not enable the various species of fungi which cause chromoblastomycosis to be distinguished from one another; they can be distinguished only by their cultural characteristics.

As in cutaneous chromoblastomycosis, the tissue reaction in this patient's nasal lesion was a complex type of chronic granuloma, in which suppurating pseudotubercles were the most characteristic feature, with polymorphonuclear leucocytes, lymphocytes, and a few plasma cells in the loose-textured intervening granulation tissue. The organisms were present both in multinucleated giant cells in the pseudotubercles and free in the purulent exudate of the microabscesses.

The histological diagnosis of chromoblastomycosis led to a belated, and unsuccessful, attempt to isolate the organism from the nose. Clinical and radiological examination showed no evidence of any abnormality 
of the nose, sinuses, ears, mouth, throat, and eyes. The patient's skin was healthy, and radiographs of his chest were normal. The operation site healed rapidly.

When the patient was last seen two years after the operation, there was no sign of any recurrence of the infection.

\section{Comment}

In spite of the unusual location of the lesion, of the failure to confirm the diagnosis by cultivation of the causative organism, and of the apparent origin of the disease in a country where this infection is not known with certainty to occur, there seems to be no reason to doubt that the case was one of chromoblastomycosis. The occurrence of chromoblastomycosis in Ceylon would not be surprising. It is, however, remarkable that the lesion should be on a mucous membrane in the first case to be recognized in a patient from that country: in other parts of the world the infection is presumed to be acquired by the direct implantation of infected material-probably soil-into the skin, the legs being particularly liable to infection because they are so frequently subjected to wounds contaminated by soil; one can only speculate on the source and mode of infection of the nasal mucosa in the case described.

In view of the original clinical diagnosis of rhinosporidiosis in this case it is important to stress that the histological distinction between the organism present in the tissues and Rhinosporidium is absolute. First, Rhinosporidium is not pigmented. Secondly, although the largest spores of Rhinosporidium are comparable in size with the chlamydospores of the fungi which cause chromoblastomycosis they differ from the latter in being more uniformly spherical, in having a much less distinct cell wall, and in the absence of septa. Finally, free spores of Rhinosporidium would not be expected in the tissue in the absence of the typical sporangia: the sporangia, which range in diameter from 100 to $350 \mu$ or more and contain great numbers of spores at various stages in development, are very conspicuous structures and their presence could not be overlooked.
This case is a further example of the need to be prepared nowadays to meet with strange diseases in countries like Britain which haveo become more cosmopolitan than was possibleo when international travel was a greater and rarer⿳亠口冋. undertaking than it is to-day. It has become more $\mathbb{\Omega}$ important than ever to have an accurate and complete history of the geographical background of ${ }_{-}^{\infty}$ every patient, and a complementary knowledge. of the diseases to which residence or travel in $\overrightarrow{\vec{\omega}}$ other countries may have exposed him. This is $\omega$ as true of, for instance, British folk who may용 have been oversea as it is of those who come from $\vec{\omega}$ abroad to visit or work in this country.

\section{REFERENCES}

Andleigh, H. S. (1953). Indian J. med. Sci., 7, 409

Burns, R. E. (1950). Canad. med. Ass. J., 63, 595.

Carrión, A. L. (1950). Ann. N.Y. Acad. Sci., 50, 1255 and Koppisch, E. (1933). Puerto Rico J. publ. Hlth, 9, $169 . \subseteq$ row, K. D., and Riddell, R. W. (1954). Proc. roy. Soc. Med., 47, 655 .

Fukushiro, R., Kagawa, S., Nishiyama, S., and Takahashi, H. (1957). $\overrightarrow{0}$ Presse méd., 65, 2142.

Kakoti, L. M., and Dey, N. C. (1957). J. Indian med. Ass., 28, 351.

Lacaz, C. da Silva (1956). Manual de Micologia Médica, 2nd ed., p. 301. Organização " Liteci," São Paulo.

Martin, D. S. (1938). Amer. J. trop. Med., 18, 421.

Meriin, J. (1930). Arch. Derm. Syph. (Berl.), 162, 300

Pedroso, A., and Gomes, J. M. (1920). An. paul. Med. Cir., 11, $53 . \supseteq$

Prokoptchouk, A. (1938). Vestn. Vener. Derm., No. 3, p. 21. (Ab-O stracted in Zbl. Haut- u. Geschl.-Kr., 1938, 60, 628.)

Sonck, C. E. (1954). Finska Läk.-Sällsk. Handl,, 97, 37. (1959a). Acta derm.-venereol. (Stockh.), 39, 300 (1959b). Arch. klin. exp. Derm., 209, 223.

Symmers, W. St. C. (1958). In Fungous Diseases and Their Treatment $\overrightarrow{\bar{O}}$ pp. 25-49, ed. Riddell, R. W., and Stewart, G. T. Butterworth, condon.

- (1960). Brain, 83, 31.

Thomas, E., Job, C. K., and Hadley, G. G. (1957). Indian J. med. Sci., 11, 570 .

Tschernjawski, J. (1929). Arch. Derm. Syph. (Berl.), 157, 196.

\section{Addendum.}

In July, 1960, while this paper was going to press, Professor Cooray told me that several cases of cutaneous chromoblastomycosis have been $\frac{}{5}$ recognized in Ceylon since June, 1959, when he $\frac{>}{O}$ prepared the information mentioned in the text on page 289. The patients have all been resi- N dents of Ceylon. The clinical and histological appearances were typical. It has not yet been $\mathrm{N}$ possible for any of the cases to be investigated mycologically. 